\title{
Níveis plasmáticos do TNF-alfa em gestantes com infecção pelo Zika vírus (ZIKV) e sua relação com gravidade da síndrome congênita: revisão sistemática e metanálise
}

\author{
Plasma TNF-alfa levels in pregnant women with Zika virus (ZIKV) infection and its relationship to \\ congenital syndrome severity: systematic review and meta-analyses \\ Niveles de TNF-alfa plasmático en mujeres embarazadas con infección por el virus Zika (ZIKV) y \\ su relación con la gravedad del síndrome congénito: revisión sistemática y metanálisis
}

\author{
Emile Ivana Fernandes Santos Costa \\ ORCID: https://orcid.org/0000-0002-6509-1279 \\ Universidade do Estado da Bahia, Brasil \\ E-mail: emilecostaivana@gmail.com \\ Murilo de Jesus Porto \\ ORCID: https://orcid.org/0000-0003-2339-8173 \\ Universidade Federal da Bahia, Brasil \\ E-mail: murilo.porto@ hotmail.com \\ Danilo Ferreira de Sousa \\ ORCID: https://orcid.org/0000-0001-9281-165X \\ Faculdade de Juazeiro do Norte, Brasil \\ E-mail: prof.danilo@ cienciadescomplicada.com \\ Camila Alexandrina Viana Figueiredo \\ ORCID: https://orcid.org/0000-0003-1356-6188 \\ Universidade Federal da Bahia, Brasil \\ E-mail: cavfigueiredo@gmail.com \\ Valdirene Leão Carneiro ${ }^{1}$ \\ ORCID: https://orcid.org/0000-0003-0655-3362 \\ Universidade do Estado da Bahia, Brasil \\ E-mail: valeao@hotmail.com
}

\begin{abstract}
Resumo
O processo patológico ocasionado pelo vírus Zika (ZIKV), que é transmitida por mosquitos do gênero Aedes, apresenta distintos sinais e sintomas, havendo uma certa dificuldade em achados de biomarcadores genéticos, bioquímicos ou imunológicos, indicando alterações a nível de tecidos alvos. Assim, o estudo tem como objetivo verificar se o aumento da expressão ou dos níveis plasmáticos de TNF-alfa em gestantes com infecção pelo ZIKV estão associados com a ocorrência/gravidade da Síndrome Congênita. Como processo metodológico, trata-se de uma revisão sistemática da literatura, seguindo as recomendações do protocolo Preferred Reporting Items for Systematic Reviews and MetaAnalyses (PRISMA) para revisões sistemáticas e metanálise. Os estudos foram pesquisados nas fontes de dados Scielo, Pubmed, LILACS e Scopus, onde todas as análises foram realizadas pelo software REVMAN 5.4 (The Cochrane Collaboration, 2020). Devido à heterogeneidade desses estudos incluídos na meta-análise, foi selecionado o modelo de efeitos aleatórios (random-effects model), sendo utilizados sete trabalhos. Os resultados e discussão indicam que os achados nos estudos indicados valores de $\mathrm{I}^{2}$ elevado $(95 \% ; \mathrm{p}<0,01)$ para o desfecho, mostrando heterogeneidade considerável, os resultados demonstram que há uma elevação considerável da citocina TNF- alfa na SCZ, sendo que o papel do TNF- alfa tanto nas doenças infecciosas quanto nas inflamações agudas e crônicas, vem sendo cada vez mais descrito, para tentar entender melhor a dinâmica da resposta de defesa do organismo as partículas invasoras que o acometem. Quando a produção de citocinas pró-inflamatórias, ficando evidente a presença de níveis plasmáticos de TNF- alfa em gestantes com infecção pelo ZIKV como marcadores biológicos.
\end{abstract}

Palavras-chave: Vírus Zika; Síndrome congênita; Níveis de TNF; Expressão de TNF; Gravidez; Gravidade.

\begin{abstract}
The pathological process caused by the Zika virus (ZIKV), which is transmitted by mosquitoes of the Aedes genus, presents different signs and symptoms, with some difficulty in finding genetic, biochemical or immunological biomarkers, indicating alterations at the level of target tissues. Thus, the study aims to verify whether the increased expression or plasma levels of TNF-alpha in pregnant women with ZIKV infection are associated with the
\end{abstract}

\footnotetext{
${ }^{1}$ Autor correspondente: Valdirene Leão Carneiro, Departamento de Ciências da Vida, Universidade do Estado da Bahia, Rua Silveira Martins, 2555, CEP: 41.150-000, Salvador, Bahia, Brasil. Tel: +55 71- 3117 2294, e-mail: valeao@hotmail.com
} 
occurrence/severity of the Congenital Syndrome. As a methodological process, it is a systematic literature review, following the recommendations of the Preferred Reporting Items for Systematic Reviews and Meta-Analyses (PRISMA) protocol for systematic reviews and meta-analysis. The studies were searched in the Scielo, Pubmed, LILACS and Scopus data sources, where all analyzes were performed using the REVMAN 5.4 software (The Cochrane Collaboration, 2020). Due to the heterogeneity of the studies included in the meta-analysis, the random-effects model was selected, and seven studies were used. The results and discussion indicate that the findings in the studies indicated high $\mathrm{I} 2$ values $(95 \% ; \mathrm{p}<0.01)$ for the outcome, showing considerable heterogeneity, the results demonstrate that there is a considerable elevation of the cytokine TNF- alpha in SCZ, being that the role of TNF- alpha both in infectious diseases and in acute and chronic inflammation has been increasingly described, in an attempt to better understand the dynamics of the body's defense response to the invading particles that affect it. When the production of proinflammatory cytokines, the presence of plasma levels of TNF- alpha in pregnant women with ZIKV infection becomes evident as biological markers.

Keywords: Zika virus; Congenital syndrome; TNF levels; TNF expression; Pregnancy; Severity.

\section{Resumen}

El proceso patológico provocado por el virus Zika (ZIKV), que es transmitido por mosquitos del género Aedes, presenta diferentes signos y síntomas, con cierta dificultad para encontrar biomarcadores genéticos, bioquímicos o inmunológicos, indicando alteraciones a nivel de tejidos diana. Por lo tanto, el estudio tiene como objetivo verificar si el aumento de la expresión o los niveles plasmáticos de TNF-alfa en mujeres embarazadas con infección por ZIKV están asociados con la aparición / gravedad del síndrome congénito. Como proceso metodológico, es una revisión sistemática de la literatura, siguiendo las recomendaciones del protocolo Preferred Reporting Items for Systematic Reviews and Meta-Analysis (PRISMA) para revisiones sistemáticas y metaanálisis. Los estudios se buscaron en las fuentes de datos Scielo, Pubmed, LILACS y Scopus, donde todos los análisis se realizaron utilizando el software REVMAN 5.4 (The Cochrane Collaboration, 2020). Debido a la heterogeneidad de los estudios incluidos en el metaanálisis, se seleccionó el modelo de efectos aleatorios y se utilizaron siete estudios. Los resultados y la discusión indican que los hallazgos en los estudios indicaron valores altos de I2 (95\%; p <0.01) para el resultado, mostrando una heterogeneidad considerable, los resultados demuestran que hay una elevación considerable de la citocina TNF- alfa en SCZ, siendo que se ha descrito cada vez más el papel del TNF- alfa tanto en enfermedades infecciosas como en la inflamación aguda y crónica, en un intento por comprender mejor la dinámica de la respuesta de defensa del organismo ante las partículas invasoras que lo afectan. Cuando se produce la producción de citocinas proinflamatorias, la presencia de niveles plasmáticos de TNF- alfa en mujeres embarazadas con infección por ZIKV se hace evidente como marcadores biológicos.

Palabras clave: Virus del Zika; Síndrome congénito; Niveles de TNF; Expresión de TNF; Embarazo; Gravedad.

\section{Introdução}

Os primeiros relatos da infecção pelo Zika vírus (ZIKV) em humanos ocorreram por volta de 1952, através do isolamento de anticorpos neutralizantes contra o ZIKV no continente africano e em pouco tempo houve registros em pacientes asiáticos, devido à proximidade geográfica entre os continentes. Até então, essas infecções possuíam características bastante limitadas, acometendo um pequeno número de pessoas que não apresentavam gravidades (Da Silva et al., 2017; Ojha et al., 2018). O ZIKV está inserido no grupo dos arbovírus, que são aqueles vírus transmitidos por artrópodes hematófagos, e pertence à família Flaviviridae que também estão outros vírus de grande importância na saúde pública, como vírus Dengue (DENV), vírus da Febre Amarela (YFV), vírus da Encefalite Japonesa e vírus Chikungunya (Petrônio et al., 2018).

Em 60 anos, menos de 20 casos de ZIKV foram confirmados na África e na Ásia, isso devido a dificuldade de diferenciar a sintomatologia (febre, erupção cutânea, artralgia, conjuntivite) entre as infecções pelos diferentes flavivírus, bem como pela reatividade cruzada com o vírus dengue (Baud et al., 2017; Musso et al., 2015). Em 2007 ocorreu um surto epidêmico na ilha Yap (Micronésia), bem como em outros países asiáticos, e entre os anos 2013 e 2014, a Polinésia Francesa viveu seu maior surto de ZIKV, e foram associados a relação entre a infecção pelo vírus Zika e desordens neurológicas, como na Síndrome de Guillain Barré e na Síndrome Congênita do Zika (De Oliveira \& Da Costa Vasconcelos, 2016; Ojha et al., 2018).

Diante do tamanho impacto social ocasionado pela infecção pelo Zika, encontramos como desafio a descoberta de biomarcadores que possam direcionar corretamente seu diagnóstico e tratamento. Numa definição geral, biomarcadores genéticos, bioquímicos ou imunológicos dizem respeito às moléculas que aumentam ou diminuem suas expressões em resposta a algum processo patológico (Schriefer \& Carvalho, 2008; M. Silva et al., 2019). 
A resposta imune que acontece durante um quadro de infecção viral, é resultado da interação das células de defesa, como macrófagos e natural killer, e as condições gerais do paciente, incluindo alimentação, comorbidades e características genéticas. O TNF- alfa pertence ao grupo das citocinas pró-inflamatórias, responsável por iniciar o combate ao microrganismo invasor através da ativação dos linfócitos T e B (M. Silva et al., 2019). Muitos estudos fizeram uma relação entre a infecção pelo ZIKV e alterações neurológicas graves, utilizando ensaios in vivo/in vitro, demonstraram que fetos expostos a níveis aumentados de TNF-alfa, no ambiente intrauterino, apresentam um quadro de neuroinflamação acentuada, prejudicando o processo da neurogênese (Lum et al., 2019; Nem de Oliveira Souza et al., 2018).

Kam et al. (2017) realizaram uma investigação para verificar o perfil imunológico de pacientes gestantes durante a fase de infecção aguda pelo ZIKV. Eles encontraram que os níveis de TNF-alfa materno foram maiores naquelas gestantes que deram luz a crianças com malformações congênitas comparados as concentrações daquelas gestantes que tiveram seus bebês normais. Esses resultados apresentados por Kam e colaboradores, levantou a possibilidade de utilizar o TNF-alfa como biomarcador de diagnostico, para garantir melhores abordagens clínica e terapêutica em futuros surtos do ZIKV. Portanto, diante da existência de poucos trabalhos disponíveis com essa temática, na literatura, torna-se necessário realizar mais trabalhos nessa linha. Assim, o presente estudo tem como objetivo verificar se o aumento da expressão ou dos níveis plasmáticos de TNF-alfa em gestantes com infecção pelo ZIKV estão associados com a ocorrência/gravidade da Síndrome Congênita.

\section{Metodologia}

\section{Estratégias de busca e seleção dos artigos}

O presente estudo trata-se de uma revisão sistemática da literatura seguindo as recomendações do protocolo Preferred Reporting Items for Systematic Reviews and Meta-Analyses (PRISMA) para revisões sistemáticas e metanálise(Fuchs \& Paim, 2010; Liberati et al., 2009; Moher et al., 2009). Os estudos foram pesquisados nas fontes de dados Scielo, Pubmed, LILACS e Scopus. Como critérios de inclusão, foram considerados trabalhos com as características a seguir: presença de pelo menos uma gestante na população de estudo; com confirmação laboratorial de infecção pelo ZIKV; apenas estudos em humanos; somente artigos publicados; cujo desenho fosse do tipo caso-controle, coorte, relato de caso; e sem restrição temporal. Foram excluídos aqueles estudos que relatavam coinfecções por outros vírus que também desencadeiam anormalidades congênitas, como STORCH (Sífilis-Toxoplasmose-Rubéola-Citomegalovírus-Herpes vírus) e arbovírus (Dengue e Chikungunya); estudos de revisão de literatura, revisão editoral, estudos in vitro/in vivo, estudos utilizando vetores, estudos com alto risco de viés, além dos estudos duplicados entre as bases de dados. A busca dos estudos foi realizada com uso dos descritores "TNF expression", "TNF level”, "severity”, “congenital zika vírus syndrome”, “congenital zika syndrome”, "pregnant”, "pregnant women”, "TNF”, "ZIKV”, combinados com os operadores boleanos AND e OR.

\section{Avaliação do risco de viés}

Para o método de avaliação do risco do viés, a presente amostra foi selecionada a partir de uma condição clínica de interesse, com as devidas buscas dos descritores, indicando em seguida a seleção dos periódicos pesquisados, sendo divididos por método de seleção, critério de escolha e qualidade das informações cabíveis no texto, sendo utilizado também recursos do sistema GRADE (https://gdt.gradepro.org/) para avaliar o risco de viés de seleção, comparabilidade, exposição e outros vieses entre os estudos. Já para avaliação do risco de viés individual foi utilizada a escala de Newcastle Ottawa Scale (NOS), para estudos observacionais do tipo caso-controle. 


\section{Extração dos dados}

Os estudos incluídos foram avaliados de forma individual por dois autores. Os dados foram extraídos em uma tabela padrão no Microsoft Word e consistem em autor/ano, objetivos, métodos, principais resultados, desfechos, síntese estatística e análise de viés.

\section{Análise estatística}

Todas as análises foram realizadas pelo software REVMAN 5.4 (The Cochrane Collaboration, 2020). Devido à heterogeneidade desses estudos incluídos na metanálise, foi selecionado o modelo de efeitos aleatórios (random-effects model). $\mathrm{O}^{2}$ foi calculado para avaliação da magnitude entre os estudos, sendo o valor de $\mathrm{I}^{2}>50 \%$ significando dizer que a heterogeneidade é substancial e $\mathrm{I}^{2}>75 \%$ quer dizer que a heterogeneidade é considerável. Já $\mathrm{o} \chi^{2}$ foi calculado para avaliar a significância dessa heterogeneidade $(\mathrm{p}<0,10)$.

\section{Resultados}

\section{Seleção dos Estudos}

A estratégia de busca utilizada nas bases de dados resultou em 81 estudos. Na triagem, 9 estudos duplicados foram excluídos, restando 72 artigos. Após a análise dos títulos e resumos de 72 artigos, 55 artigos foram excluídos, sendo 13 artigos de revisão; 33 desenhos de estudos não desejados; e 11 artigos com assunto diferente do que foi pesquisado. Dos 17 estudos elegíveis, 10 foram excluídos pois os artigos não apresentaram a síndrome congênita como desfecho principal. As buscas nas bases de dados resultaram em vinte e sete artigos incluídos na revisão sistemática e sete (se houver) na metanálise (Figura 1).

\section{Características dos Estudos}

Os estudos incluídos na revisão sistemática foram conduzidos em centros de pesquisas e laboratórios hospitalares de várias regiões do Brasil. O desenho dos estudos incluídos foi observacional do tipo caso-controle. Os estudos incluíram participantes com diagnostico laboratorial confirmado de infecção pelo ZIKV, através dos testes de RT-PCR e/ou dosagem de IgM/IgG contra antígenos do vírus. A descrição detalhada dos estudos incluídos está representada no Quadro 1. 
Figura 1: Fluxograma de seleção dos estudos.

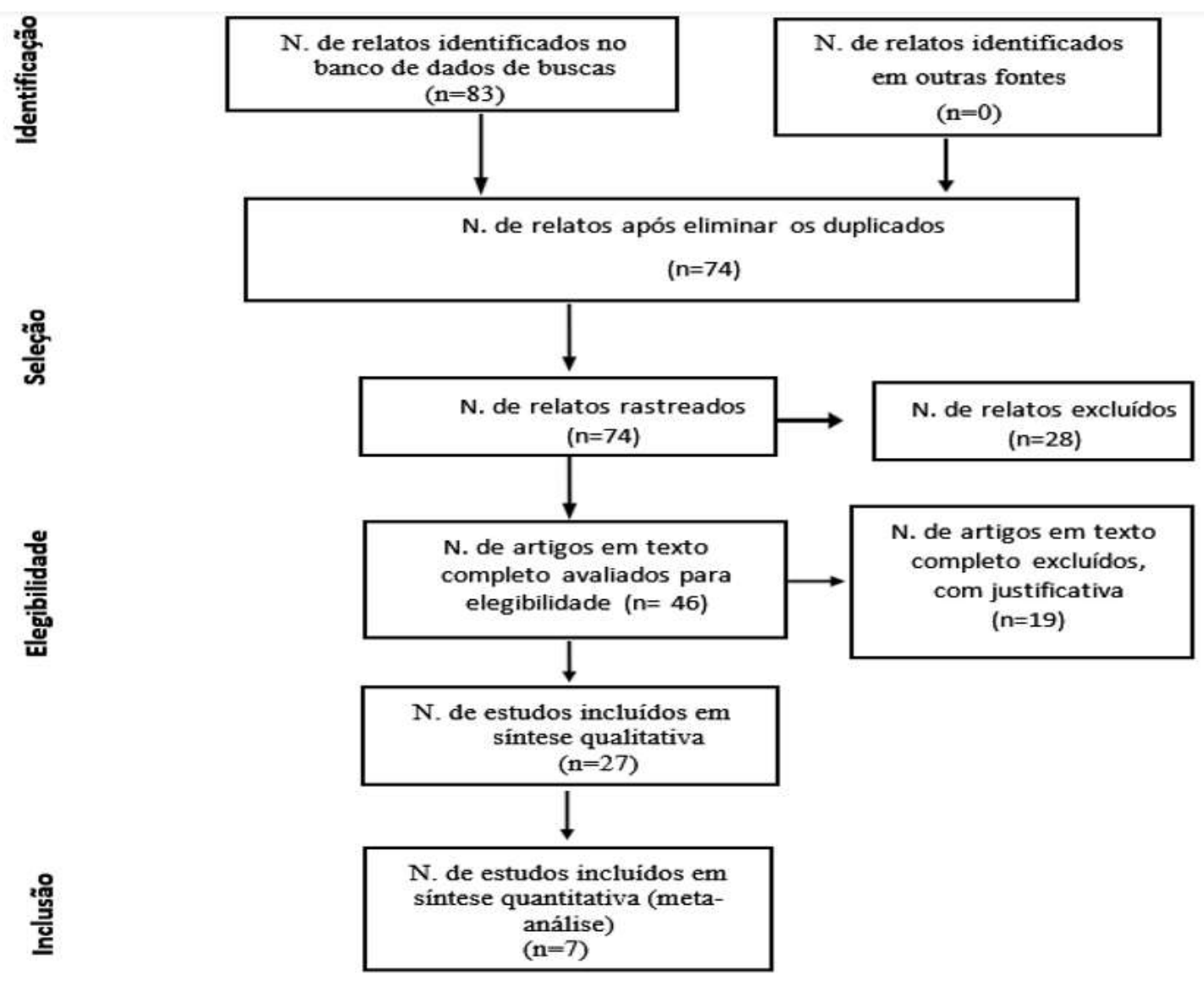

Fonte: Autores (2021). 
Quadro 1: Características dos estudos incluídos.

\begin{tabular}{|c|c|c|c|c|c|c|}
\hline Autor/ano & Objetivo & Método & Principais resultados & Desfechos & Síntese estatística & Análise de viés \\
\hline $\begin{array}{l}\text { CAMACHO- } \\
\text { ZAVALA et al., } \\
2021\end{array}$ & $\begin{array}{l}\text { Descrever o papel da } \\
\text { gravidez na resposta } \\
\text { sistêmica pró e anti- } \\
\text { inflamatória durante a } \\
\text { infecção sintomática do } \\
\text { ZIKV. }\end{array}$ & Caso-controle & $\begin{array}{l}\text { As gestantes com infecção por } \\
\text { ZIKV apresentaram um } \\
\text { aumento significativo nas } \\
\text { citocinas IL-10 e pró- } \\
\text { inflamatórias IL-6, TNF- alfa, } \\
\text { IL-17A, IFN- } \alpha \text { e IFN- } \gamma \text { mas } \\
\text { não IL-1 } \beta \text {, o que pode } \\
\text { influenciar no desfecho da } \\
\text { SCZ. }\end{array}$ & $\begin{array}{l}\text { Os dados mostram que } \\
\text { mulheres não grávidas e } \\
\text { grávidas infectadas pelo } \\
\text { ZIKV mostram a resposta } \\
\text { ampla e anti-inflamatória } \\
\text { esperada com altos níveis de } \\
\text { citocinas e atividade antiviral } \\
\text { provavelmente mediada pelo } \\
\text { IFN- } \gamma \text {. }\end{array}$ & 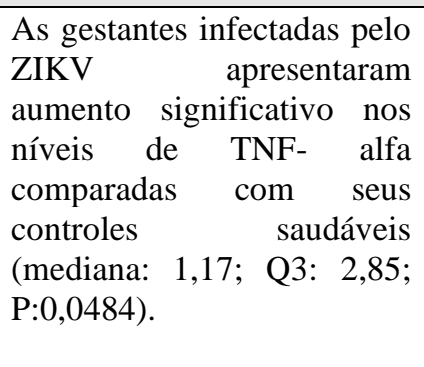 & Moderado \\
\hline $\begin{array}{l}\text { DA SILVA et al., } \\
2019\end{array}$ & $\begin{array}{l}\text { Avaliar a expressão de } \\
\text { mRNA de receptores da } \\
\text { imunidade inata, suas } \\
\text { moléculas adaptadoras } \\
\text { e citocinas em } \\
\text { pacientes na fase aguda } \\
\text { da infecção pelo ZIKV. }\end{array}$ & Caso-controle & $\begin{array}{l}\text { Os pacientes infectados pelo } \\
\text { ZIKV apresentaram expressão } \\
\text { reduzida de RIG-1, TLR8, } \\
\text { Myd88, TNF-alfa. }\end{array}$ & $\begin{array}{l}\text { Durante a gestação, mulheres } \\
\text { infectadas com } \begin{array}{l}\text { ZIKV } \\
\text { apresentaram }\end{array} \text { níveis } \\
\text { aumentados de mediadores } \\
\text { imunológicos como TNF- } \alpha .\end{array}$ & & Moderado \\
\hline KAM et al., 2017 & $\begin{array}{l}\text { Investigar a resposta } \\
\text { clínica e imunológica, } \\
\text { com foco no perfil de } \\
\text { mediadores } \\
\text { imunológicos em } 95 \\
\text { pacientes adultos } \\
\text { infectados pelo ZIKV. }\end{array}$ & Caso-controle & $\begin{array}{lr}\text { Gestantes portadoras de feto } \\
\text { com anomalias } & \text { do } \\
\text { desenvolvimento } & \text { fetal } \\
\text { apresentaram níveis } & \text { muitos } \\
\text { altos de TNF-alfa. } & \end{array}$ & $\begin{array}{lcr}\text { Altos níveis } & \text { de } & \text { TNF- } \alpha \\
\text { detectáveis } & \text { na } & \text { maior } \\
\text { gravidade da SCZ. } & \end{array}$ & 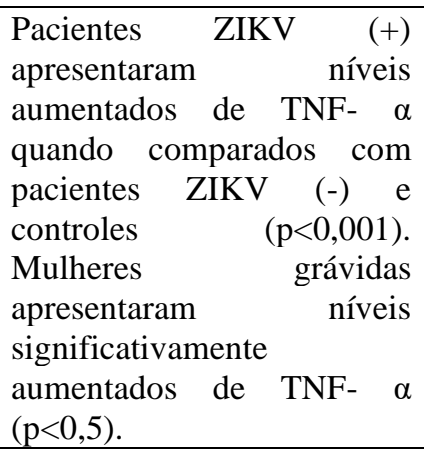 & Moderado \\
\hline $\begin{array}{lll}\text { NAVECA et al., } \\
2018\end{array}$ & $\begin{array}{l}\text { Definir } \\
\text { biomarcadores } \\
\text { imunológicos que se } \\
\text { correlacionam com a } \\
\text { infecção aguda por } \\
\text { ZIKV. }\end{array}$ & Caso-controle & $\begin{array}{l}\text { Os pacientes infectados pelo } \\
\text { ZIKV apresentaram resposta } \\
\text { inflamatória } \\
\text { aumentada. Entretanto, os } \\
\text { níveis da citocina TNF- } \alpha \\
\text { encontrados nos mesmos } \\
\text { estavam reduzidos nos } \\
\text { indivíduos do grupo caso, } \\
\text { quando comparados aos seus } \\
\text { controles. }\end{array}$ & $\begin{array}{l}\text { Uma resposta aumentada de } \\
\text { diversos biomarcadores em } \\
\text { diferentes momentos da } \\
\text { infecção pelo ZIKV, } \\
\text { demonstraram que há uma } \\
\text { associação entre os níveis } \\
\text { dessas citocinas e a } \\
\text { permeabilidade da barreira } \\
\text { hematoencefálica } \\
\text { neuroinvasão, o que reflete no }\end{array}$ & $\begin{array}{l}\text { Níveis de TNF- } \alpha \text { de } 29 \\
\text { mulheres foram dosados } \\
\text { encontrando as seguintes } \\
\text { concentrações: } 9,76 \text { (IC: } \\
6,10-20,20 \text { ) pg } / \mathrm{mL} \text { (não } \\
\text { infectadas) e } 35,87 \text { (IC: } \\
\begin{array}{l}25,45-44,08) \\
\text { (infectadas) com } \mathrm{p}=0,0001 .\end{array}\end{array}$ & Moderado \\
\hline
\end{tabular}




\begin{tabular}{|c|c|c|c|c|c|c|}
\hline & & & & $\begin{array}{l}\text { desfecho de gravidade da } \\
\text { SCZ. }\end{array}$ & & \\
\hline SANTOS et al., 2019 & $\begin{array}{l}\text { Testar SNPs em genes } \\
\text { candidatos CD209, } \\
\text { TNF- } \alpha, \text { CXCL8, IL-6, } \\
\text { CCL-2, TLR-3, TRL-4 } \\
\text { e MICB para investigar } \\
\text { sua associação com a } \\
\text { SCZ. }\end{array}$ & Caso-controle & $\begin{array}{l}\text { O SNP rs3775291 no gene } \\
\text { TLR-3 desencadeia respostas } \\
\text { antivirais em mães infectadas } \\
\text { pelo ZIKV durante a gravidez, } \\
\text { e está associado a ocorrência } \\
\text { da SCZ; } \\
\text { O SNP rs1799964 no gene } \\
\text { TNF-alfa em bebês com SCZ } \\
\text { está associado a microcefalia } \\
\text { grave. }\end{array}$ & $\begin{array}{l}\text { Variações nos genes TLR3 e } \\
\text { TNF } \alpha \text { associadas a respostas } \\
\text { imunes inatas em mães } \\
\text { grávidas infectadas com } \\
\text { ZIKV e seus bebês CZS } \\
\text { podem influenciar o risco de } \\
\text { ocorrência e gravidade da } \\
\text { microcefalia }\end{array}$ & 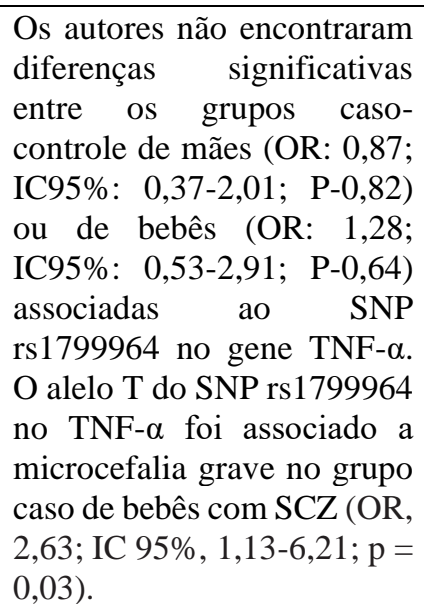 & Moderado \\
\hline $\begin{array}{l}\text { VINHAES et al., } \\
2020\end{array}$ & $\begin{array}{l}\text { Compreender o perfil } \\
\text { inflamatório e o grau de } \\
\text { inflamação das pessoas } \\
\text { infectadas pelo ZIKV. }\end{array}$ & Caso-controle & $\begin{array}{l}\text { Recém-nascidos com } \\
\text { microcefalia apresentaram } \\
\text { níveis de citocinas, como } \\
\text { TNF-alfa, aumentados de } \\
\text { maneira marcante. }\end{array}$ & $\begin{array}{l}\text { Intenso } \\
\text { inflamatório proporcional à } \\
\text { gravidade da microcefalia } \\
\text { associada ao ZIKV, com } \\
\text { aumento do TNF- } \alpha \text {. }\end{array}$ & $\begin{array}{l}\text { Foram detectados que } \\
\text { crianças com microcefalia } \\
\text { apresentaram } 66,93 \quad(21,83- \\
130,72) \text { pg/mL, enquanto } \\
\text { aquelas que mesmo após } \\
\text { exposição ao ZIKV não } \\
\text { desenvolveram microcefalia } \\
\text { apresentaram 23,26 (7,88- } \\
56,03) \mathrm{pg} / \mathrm{mL}(\mathrm{p}<0,01) \text {. }\end{array}$ & Moderado \\
\hline $\begin{array}{l}\text { BARROS et al., } \\
2018\end{array}$ & $\begin{array}{l}\text { Determinar o perfil de } \\
\text { ativação imune } \\
\text { sistêmica durante a } \\
\text { infecção aguda pelo } \\
\text { ZIKV em residentes de } \\
\text { uma área endêmica e } \\
\text { determinar se } \\
\text { diferentes sintomas } \\
\text { estavam relacionados a } \\
\text { níveis diferenciais de } \\
\text { citocinas / quimiocinas } \\
\text { específicas }\end{array}$ & Caso-controle & $\begin{array}{l}\text { Pacientes com infecção pelo } \\
\text { ZIKV apresentaram níveis de } \\
\text { TNF-alfa reduzidos. }\end{array}$ & $\begin{array}{l}\text { Infecção aguda pelo ZIKV } \\
\text { exibe um perfil de ativação } \\
\text { imune sistêmico modesto, } \\
\text { envolvendo citocinas e } \\
\text { quimiocinas pró-inflamatórias } \\
\text { e imunorreguladoras. }\end{array}$ & $\begin{array}{l}\text { A concentração de TNF- } \alpha \\
\text { plasmático foi reduzida nos } \\
\text { pacientes com infecção } 0,06 \\
\mathrm{pg} / \mathrm{mL}(\mathrm{p}<0,05) \text {. }\end{array}$ & Moderado \\
\hline
\end{tabular}

*SCZ: Síndrome Congênita do Zika; ZIKV: Vírus Zika; SNP: Polimorfismo de Nucleotídeo Único. Fonte: Autores (2021). 


\section{Risco de viés}

Sobre o viés de seleção, todos os estudos $(7 / 7 ; 100 \%)$ utilizaram amostra por conveniência para a composição dos grupos caso-controle, não havendo randomização desses participantes. Isso está associado a um alto risco de viés, já que não houve seleção através do sorteio, caracterizando o cegamento inclusive um dos artigos relata que a alocação dos participantes foi realizada em diferentes regiões do Brasil, o que aumenta esse tipo de viés, pois os autores estão trabalhando com amostra expostas a condições ambientais, sociais e genéticas bastante variadas (Figura 2 e Quadro 2).

Figura 2: Avaliação de viés entre os estudos (sistema GRADE).

\begin{tabular}{|c|c|c|c|c|c|c|c|c|c|c|c|c|}
\hline \multicolumn{7}{|c|}{ Avaliação de certeza } & \multicolumn{2}{|c|}{$\mathbf{N}^{\circ}$ de pacientes } & \multicolumn{2}{|c|}{ Efeito } & \multirow{2}{*}{ Certeza } & \multirow{2}{*}{ Importância } \\
\hline $\begin{array}{l}\text { № dos } \\
\text { estudos }\end{array}$ & $\begin{array}{c}\text { Delineamento } \\
\text { do estudo }\end{array}$ & $\begin{array}{l}\text { Risco de } \\
\text { viés }\end{array}$ & Inconsistência & $\begin{array}{l}\text { Evidência } \\
\text { indireta }\end{array}$ & Imprecisão & $\begin{array}{c}\text { Outras } \\
\text { considerações }\end{array}$ & TNF & $\begin{array}{c}\text { Sem a } \\
\text { característica }\end{array}$ & $\begin{array}{c}\text { Relativo } \\
\text { (95\% IC) }\end{array}$ & $\begin{array}{l}\text { Absoluto } \\
\text { (95\% IC) }\end{array}$ & & \\
\hline \multicolumn{13}{|c|}{ Novo desfecho } \\
\hline \multirow[t]{2}{*}{7} & \multirow[t]{2}{*}{$\begin{array}{c}\text { estudo } \\
\text { observacional }\end{array}$} & \multirow[t]{2}{*}{ não grave } & \multirow[t]{2}{*}{ não grave } & \multirow[t]{2}{*}{ não grave } & \multirow[t]{2}{*}{ não grave } & \multirow{2}{*}{$\begin{array}{l}\text { todos os potenciais } \\
\text { fatores de confusão } \\
\text { reduziriam o efeito } \\
\text { demonstrado }\end{array}$} & \multicolumn{2}{|c|}{277 casos 54 controles } & \multirow[t]{2}{*}{ não combinado } & - & \multirow[t]{2}{*}{$\begin{array}{c}\oplus \oplus \oplus \bigcirc \\
\text { MODERADA }\end{array}$} & \multirow[t]{2}{*}{ CRÍTICO } \\
\hline & & & & & & & - & $30.0 \%$ & & $\begin{array}{c}\text { não } \\
\text { combinado }\end{array}$ & & \\
\hline
\end{tabular}

IC: Intervalo de Confiança

Fonte: Autores (2021). 
Research, Society and Development, v. 10, n. 10, e428101019080, 2021

(CC BY 4.0) | ISSN 2525-3409 | DOI: http://dx.doi.org/10.33448/rsd-v10i10.19080

Quadro 2: Newcastle-Ottawa escala dos estudos incluídos.

\begin{tabular}{|c|c|c|c|c|c|c|c|c|}
\hline & \multicolumn{4}{|c|}{ Seleção } & Comparabilidade & \multicolumn{3}{|c|}{ Exposição } \\
\hline Estudo & $\begin{array}{l}\text { Definição } \\
\text { adequada dos } \\
\text { casos }\end{array}$ & $\begin{array}{l}\text { Representatividade } \\
\text { dos casos }\end{array}$ & $\begin{array}{l}\text { Seleção dos } \\
\text { controles }\end{array}$ & $\begin{array}{l}\text { Definição } \\
\text { dos } \\
\text { controles }\end{array}$ & $\begin{array}{l}\text { Comparação entre os } \\
\text { casos e controles }\end{array}$ & Averiguação & $\begin{array}{l}\text { Comparação entre os } \\
\text { métodos de investigação entre } \\
\text { os casos e controles }\end{array}$ & $\begin{array}{l}\text { Taxa de } \\
\text { não } \\
\text { resposta }\end{array}$ \\
\hline $\begin{array}{l}\text { CAMACHO- } \\
\text { ZAVALA et al., } \\
2021\end{array}$ & * & & $*$ & $*$ & $*$ & $*$ & $*$ & * \\
\hline $\begin{array}{l}\text { DA SILVA et al., } \\
2019\end{array}$ & $*$ & & $*$ & $*$ & $*$ & $*$ & $*$ & * \\
\hline $\begin{array}{l}\text { BARROS et al., } \\
2018\end{array}$ & $*$ & & $*$ & $*$ & $*$ & $*$ & $*$ & $*$ \\
\hline KAM et al., 2017 & $*$ & & $*$ & $*$ & $*$ & $*$ & $*$ & $*$ \\
\hline $\begin{array}{l}\text { NAVECA et al., } \\
2018\end{array}$ & $*$ & & $*$ & $*$ & $*$ & $*$ & $*$ & $*$ \\
\hline $\begin{array}{l}\text { SANTOS et al., } \\
2019\end{array}$ & * & & $*$ & $*$ & $*$ & $*$ & $*$ & $*$ \\
\hline $\begin{array}{l}\text { VINHAES et al., } \\
2020\end{array}$ & $*$ & & $*$ & $*$ & $*$ & $*$ & $*$ & $*$ \\
\hline
\end{tabular}

Fonte: Autores (2021). 


\section{Metanálise}

Sete estudos foram incluídos na metanálise (Barros et al., 2018; Camacho-Zavala et al., 2021; Kam et al., 2017; Naveca et al., 2018; Santos et al., 2019; L. B. Silva et al., 2019; Vinhaes et al., 2020). Todos apresentaram o valor de I $^{2}$ elevado (95\%; p<0,01) para o desfecho. Mesmo com heterogeneidade considerável, os resultados demonstram que há uma elevação considerável da citocina TNF- $\alpha$ na SCZ (Figura 3).

Figura 3: Forest plot.

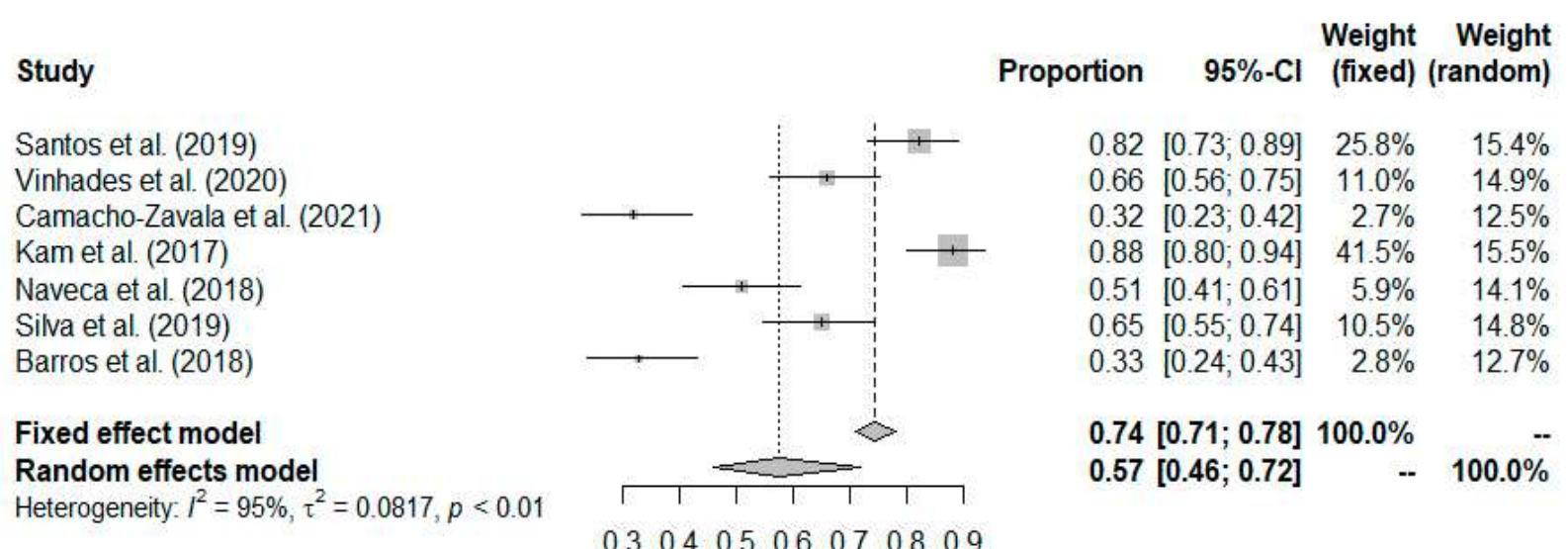

Fonte: Autores (2021).

\section{Discussão}

As citocinas são pequenas moléculas, de aproximadamente 5-20 kDa, essenciais para o processo de sinalização celular, incluindo a ativação do sistema imunológico, através da modulação do comportamento das células de defesa próximas, ou até mesmo distantes do local da infecção por microrganismos invasores. Fazem parte dessas moléculas as interleucinas (IL), interferons (IFNs), fatores de crescimento (FC), quimiocinas (CKs) e fator de necrose tumoral (TNF). O TNF- alfa é uma citocina pró-inflamatória multifuncional, produzida principalmente pelos macrófagos, com papel muito importante na ativação das respostas imunes inata e adaptativa juntamente com interleucinas do tipo IL-1 $\alpha$, IL-1 $\beta$, IL-6 e IL-8 (Higuchi et al., 1998 \& Silva et al., 2019).

O papel do TNF- alfa tanto nas doenças infecciosas quanto nas inflamações agudas e crônicas, vem sendo cada vez mais descrito, para tentar entender melhor a dinâmica da resposta de defesa do organismo as partículas invasoras que o acometem. Quando a produção de citocinas pró-inflamatórias ocorre em excesso, aumenta a resposta imune do hospedeiro, porém causa efeitos deletérios a homeostase do organismo, já que para ocorrer uma resposta imune adequada é necessária uma comunicação equilibrada entre as células, o ambiente e a genética do hospedeiro (Silva et al., 2019).

Neste estudo foi demonstrado que o aumento da expressão ou dos níveis plasmáticos de TNF- alfa em gestantes com infecção pelo ZIKV estão associados com a ocorrência/gravidade da Síndrome Congênita, nos estudos incluídos nesta metanálise, há realmente um aumento da expressão e/ou concentração dessa citocina tão importante na modulação da resposta imune.

Embora as citocinas representem um grupo de moléculas que apresentam níveis aumentados no plasma sanguíneo, elas na maioria dos casos, estão associadas a sintomas mais leves da infecção pelo ZIKV. Isso pode ser explicado por um equilíbrio entre citocinas pró e antinflamatórias, e as quimiocinas, considerado um distúrbio homeostático imune associado ao desacoplamento da inflamação sistêmica, desenvolvido através de uma reatividade imunológica cruzada entre os arbovírus 
ZIKV, dengue (DENV) e febre amarela (AFV), além do alto índice de vacinação contra a AFV nas regiões endêmicas onde há co-circulação desses vírus (BRASIL, 2015; Maciel et al., 2008).

Nos estudos de Camacho-Zavala et al. (2021) e Barros et al. (2018) não foi descrito aumento da expressão/níveis de TNF- alfa nos grupos casos, representados por crianças microcefálicas que foram expostas ao ZIKV durante a vida intrautrina, o que pode ser confirmado estatisticamente pelo florest plot da nossa metanálise com valores de 0.32 e 0.33 (IC 0.23-.42; e IC 0.24-0.43; $\mathrm{p}<0,01$, respectivamente). Já no estudo de Silva et al. (2019) foram avaliadas amostras de trinta pacientes, dez com infecção confirmada pelo ZIKV através da técnica de RT-PCR, que fazem parte do grupo caso e vinte controles saudáveis. Eles realizaram a dosagem de citocinas para verificar o comportamento delas durante a infecção aguda pelo ZIKV e observaram que houve uma baixa produção de TNF- alfa no plasma dos pacientes do grupo caso quando comparados com o grupo controle, com um valor de efeito 0.65 (IC 0.55-.74; p<0,01) encontrado em nossa metanálise.

O equilíbrio inflamatório sistêmico é um possível fator de proteção que o organismo humano desenvolveu contra a infecção viral pelo Zika, por isso provavelmente existe algum fator secundário à resposta inflamatória acentuada, intensificando a coordenação desses processos que levam ao quadro de neuroinflamação acarretando o desfecho da microcefalia. Apesar do mecanismo da resposta imune antiviral ainda não ter sido totalmente elucidada, ela pode ser desencadeada pela regulação viral da expressão dos receptores de reconhecimento de padrões (PRRs) envolvidos nas vias de resposta inflamatória antiviral (Hamel et al., 2015).

Naveca et al. (2018), observaram que a resposta imunológica que se estabelece durante a fase aguda da infecção pelo ZIKV é polifuncional e altamente inflamatória, demonstrando níveis elevados de diversas citocinas, quimiocinas e fatores de crescimento plasmáticos no grupo caso quando comparado com os controles. Entretanto, os níveis de TNF- alfa encontrados nesse estudo estavam reduzidos, podendo ser justificado pela atividade da adenosina monofosfato quinase (AMPK), que possui uma importante função antiviral, atuando como um sinalizador celular, capaz de alterar a resposta imunológica do hospedeiro durante a infecção pelo vírus. Vários estudos demonstraram que os níveis de AMPK estão inversamente relacionados com a intensidade da inflamação, o que significa que, em condições inflamatórias, essa proteína quinase apresentará atividade reduzida, sugerindo que a essa molécula promove uma resposta antiviral e que sua baixa regulação em células endoteliais infectadas pode ser uma estratégia usada pelo ZIKV para manobrar o sistema imunológico da célula hospedeira (Kerui et al., 2018; Kumar et al., 2016a, 2016b; Moreira et al., 2016). Os autores descreveram ainda, que as concentrações plasmáticas de TNF- alfa e CCL5 (uma quimiocinas) apresentavam uma forte correlação com as porcentagens de neutrófilos e linfócitos durante a fase aguda da infecção, o que pode ser justificado pela presença dessas moléculas atraindo leucócitos, fato que demonstra o importante papel das mesmas na defesa imunológica, inata e adaptativa, em resposta à infecção pelo ZIKV (Rabelo et al., 2018, 2020; Singh et al., 2020).

Kam et al. (2017) avaliaram uma coorte de pacientes brasileiros de Campinas (SP), onde na época do estudo, a imunização contra a AFV não fazia parte do calendário vacinal obrigatório do SUS, e para investigar a resposta clínica e imunológica de 95 pacientes adultos com sintomas da infecção pelo ZIKV, sendo 6 dessas, gestantes. Ao nascer, amostras dos 6 recém-nascidos dessas gestantes e de 4 outros recém-nascidos também foram coletadas para avaliação dos desfechos da infecção nessas crianças. A confirmação da infecção foi realizada através de RT-PCR em tempo real e ELISA especifica para detecção de anticorpos do tipo IgG. Foram incluídos ao estudo 13 indivíduos saudáveis para composição do grupo controle. A fim de construir um perfil de resposta imunológica no quadro da infecção pelo ZIKV, eles mediram as citocinas plasmáticas através do imunoensaio baseado em microesfera multiplex, a quantificaram os níveis de TNF- alfa. Os níveis de várias citocinas pró-inflamatórias, como TNF- alfa, apresentaram aumento significativo quando comparados ao grupo controle, sugerindo uma produção ativa desses mediadores imunológicos durante a fase aguda da infecção. Do total de 10 recém-nascidos que foram expostos à infecção pelo ZIKV durante a vida intrauterina, apenas 2 nasceram com malformações congênitas. 
Quando os autores avaliaram o perfil das grávidas com a infecção que pariram as crianças com anormalidades cerebrais, detectaram níveis muito altos de mediadores imunológicos, incluindo TNF- alfa, quando comparado com as grávidas que tiveram seus bebês normais. As concentrações de TNF- alfa apresentaram resultados significativamente maiores durante a fase aguda do que a fase de convalescência da infecção, e ainda os autores destacam a importância dessa citocina ser mais bem avaliada como biomarcador de prognostico para desfechos desfavoráveis à nível de sistema nervoso central (SNC). Esses dados estão em concordância com os nossos resultados, sendo esse estudo de Kam et al. (2017) aquele que representou o maior efeito $(0,88)$ entre os níveis aumentados de TNF- alfa com a maior gravidade da SCZ (IC 0.80-0.94; p<0,01).

Vinhaes et al. (2020) descreveram um estudo do tipo caso-controle comparando concentrações plasmáticas de biomarcadores inflamatórios de vinte e duas crianças que apresentaram microcefalia ao nascer, catorze crianças sem microcefalia (apesar do contato com o ZIKV) e catorze crianças saudáveis de mães não expostas ao ZIKV. A confirmação da infecção pelo ZIKV foi realizada pelo teste do RT-PCR e IgM contra o vírus. Eles avaliaram vinte e seis marcadores imunológicos envolvidos no processo da inflamação, entre eles o TNF- alfa, que por sua vez apresentou concentração aumentada diante do quadro microcefálico quando comparados aos seus controles saudáveis, o que confirma o nosso resultado, mostrando que existe uma relação de 0.66 entre a elevação dos níveis do TNF- alfa e o desfecho de microcefalia (IC 0.56-0.75; p<0,01).

Diversos estudos tentam elucidar a fisiopatologia do desfecho da microcefalia em crianças que foram expostas ao ZIKV ainda no útero. O que já se sabe é que a presença dessa infecção desregula a expressão dos genes associados à resposta imune, ciclo celular, diferenciação e morte celular por apoptose em células progenitoras neurais (Faizan et al., 2016; Tang et al., 2016).A ativação do receptor toll like 3 (TRL3) é capaz de desencadear resposta imune antiviral através da produção de citocinas próinflamatórias. O ZIKV é capaz de ativar respostas imunes inatas mediadas pelo TRL3 causando um desequilíbrio na rede de genes responsáveis pelos processos de neurogênese e apoptose. A ativação dessa resposta imunológica é importante para manter a barreira hematoencefálica (Bayer et al., 2016; Dang et al., 2016).

Santos et al. (2019) selecionaram setenta mulheres que tiveram bebês com SCZ no período entre 2015 e 2017, sendo uma dessas mães tinha gêmeos monozigóticos, ambos acometidos com a SCZ, o grupo caso foi composto por setenta e uma crianças e mais trinta pais, já o grupo controle foi composto por quarenta e quatro mães e seus filhos saudáveis. Eles encontraram uma associação entre o risco de SCZ e a presença do alelo T (SNP rs3775291) no gene TRL3 de mulheres que foram infectadas pelo ZIKV durante a gravidez, apresentando maior suscetibilidade à ocorrência da SCZ. Alguns estudos de genética das populações mostraram associação entre esse SNP e suscetibilidade a infecções virais, apesar disso, como isso acontece ainda não está totalmente definido. A presença do alelo $\mathrm{T}$ foi considerado como fator de proteção para dengue hemorrágica (Alagarasu et al., 2015), além de controlar a replicação viral na encefalite transmitida por carrapatos (Kindberg et al., 2011), e na infecção pelo HIV-1 de células mononucleares in vitro, sendo também observado um aumento de citocinas pró-inflamatórias, como a TNF- alfa, nas células que apresentavam pelo menos um alelo T nesse SNP (Sironi et al., 2012). Contudo, corroborando com os achados de Santos et al. (2019), o estudo de (Studzińska et al., 2017) mostrou que a presença de pelo menos um alelo T do SNP s3775291 aumenta o risco de infecções por citomegalovírus em crianças.

Uma associação também foi observada entre o alelo T (SNP rs1799964) no gene TNF- alfa e a ocorrência da microcefalia grave nas crianças com microcefalia. A presença desse alelo $\mathrm{T}$ em crianças recém-nascidas sugere uma resposta inflamatória acentuada, o que reduz a defesa do feto contra o vírus, consequentemente aumentando a carga viral do ZIKV e seu potencial de causar anormalidades nos neurônios fetais (Higuchi et al., 1998; Kasztelewicz et al., 2017), estando em concordância com os nossos resultados, já que o estudo do Silva et al. (2019) apresentou 0.82 (IC 0.73-0.89; p<0,01) de relação entre a elevação do TNF- alfa e a presença da microcefalia em recém-nascidos.

Importante ressaltar que a maioria dos estudos encontrados com estatística significativa mostra o perfil das grávidas com a infecção que pariram as crianças com anormalidades cerebrais, foi encontrado níveis muito altos de mediadores 
imunológicos, incluindo TNF- alfa, quando comparado com as grávidas que tiveram seus bebês normais, além disso as concentrações de TNF- alfa apresentaram resultados elevados durante a fase aguda do que a fase de convalescência da infecção. O resultado da nossa metanálise sugere que o aumento dos níveis do TNF- alfa está associado com o aumento da gravidade da SCZ.

\section{Considerações Finais}

A produção científica sobre a existência de um biomarcador de gravidade da infecção pelo ZIKV ainda é escassa. Os dados aqui apresentados demonstram existir uma relação entre a presença da citocina TNF- alfa e a gravidade do ZIKA vírus e mais estudos envolvendo este marcador devem ser realizados a fim de elucidar esta possibilidade. Outros estudos, com um melhor delineamento metodológico, devem ser realizados para que seja possível ampliar o entendimento sobre o comportamento das citocinas pró-inflamatórias, no contexto do desenvolvimento e gravidade da Síndrome Congênita do Zika vírus, a fim de contribuir para o prognóstico, diagnóstico e tratamento desse desfecho.

\section{Referências}

Alagarasu, K., Bachal, R. V., Damle, I., Shah, P. S., \& Cecilia, D. (2015). Association of FCGR2A p.R131H and CCL2 c.-2518 A > G gene variants with thrombocytopenia in patients with dengue virus infection. Human Immunology, 76(11), 819-822. https://doi.org/10.1016/J.HUMIMM.2015.09.042

Barros, J. B. de S., da Silva, P. A. N., Koga, R. de C. R., Gonzalez-Dias, P., Filho, J. R. C., Nagib, P. R. A., Coelho, V., Nakaya, H. I., Fonseca, S. G., \& Pfrimer, I. A. H. (2018). Acute Zika virus infection in an endemic area shows modest proinflammatory systemic immunoactivation and cytokine-symptom associations. Frontiers in Immunology, 9(MAY). https://doi.org/10.3389/fimmu.2018.00821

Baud, D., Gubler, D. J., Schaub, B., Lanteri, M. C., \& Musso, D. (2017). An update on Zika virus infection. In The Lancet (Vol. 390, Issue 10107, pp. 20992109). Lancet Publishing Group. https://doi.org/10.1016/S0140-6736(17)31450-2

Bayer, A., Lennemann, N. J., Ouyang, Y., Bramley, J. C., Morosky, S., Marques, E. T. D. A., Cherry, S., Sadovsky, Y., \& Coyne, C. B. (2016). Type III Interferons Produced by Human Placental Trophoblasts Confer Protection against Zika Virus Infection. Cell Host \& Microbe, 19(5), 705-712. https://doi.org/10.1016/J.CHOM.2016.03.008

BRASIL. (2015). Ministério da Saúde Secretaria Atenção à Saúde Protocolo De Atenção À Saúde E Resposta À Ocorrência De Microcefalia Relacionada À Infecção Pelo Vírus Zika. www.saude.g

Camacho-Zavala, E., Santacruz-Tinoco, C., Muñoz, E., Chacón-Salinas, R., Salazar-Sanchez, M. I., Grajales, C., González-Ibarra, J., Borja-Aburto, V. H., Jaenisch, T., \& Gonzalez-Bonilla, C. R. (2021). Pregnant Women Infected with Zika Virus Show Higher Viral Load and Immunoregulatory Cytokines Profile with CXCL10 Increase. Viruses, 13(1). https://doi.org/10.3390/v13010080

Da Silva, E., Maria, A., Sangiovo, B., Suelen, F., Pereira, O., Eickhoff, C., \& Casalini, C. (2017). Zika Vírus: Fatores Evolutivos Determinantes Para Sua Epidemia E Patogenia. In Revista Saúde Integrada. http://local.cnecsan.edu.br/revista/index.php/saude/index

da Silva, M. H. M., Moises, R. N. C., Alves, B. E. B., Pereira, H. W. B., de Paiva, A. A. P., Morais, I. C., Nascimento, Y. M., Monteiro, J. D., de Souto, J. T., Nascimento, M. S. L., de Araújo, J. M. G., da Guedes, P. M. M., \& Fernandes, J. V. (2019). Innate immune response in patients with acute Zika virus infection. Medical Microbiology and Immunology, 208(6). https://doi.org/10.1007/s00430-019-00588-8

Dang, J., Tiwari, S. K., Lichinchi, G., Qin, Y., Patil, V. S., Eroshkin, A. M., \& Rana, T. M. (2016). Zika Virus Depletes Neural Progenitors in Human Cerebral Organoids through Activation of the Innate Immune Receptor TLR3. Cell Stem Cell, 19(2), 258-265. https://doi.org/10.1016/J.STEM.2016.04.014

De Oliveira, C. S., \& Da Costa Vasconcelos, P. F. (2016). Microcephaly and Zika virus. Jornal de Pediatria, 92(2), 103-105. https://doi.org/10.1016/j.jped.2016.02.003

Faizan, M. I., Abdullah, M., Ali, S., Naqvi, I. H., Ahmed, A., \& Parveen, S. (2016). Zika Virus-Induced Microcephaly and Its Possible Molecular Mechanism. Intervirology, 59(3), 152-158. https://doi.org/10.1159/000452950

Fuchs, S. C., \& Paim, B. S. (2010). Seção de bioestatística revisão sistemática de estudos observacionais com metanálise. Hcpa, 30(3), $294-301$.

Hamel, R., Dejarnac, O., Wichit, S., Ekchariyawat, P., Neyret, A., Luplertlop, N., Perera-Lecoin, M., Surasombatpattana, P., Talignani, L., Thomas, F., CaoLormeau, V.-M., Choumet, V., Briant, L., Desprès, P., Amara, A., Yssel, H., \& Missé, D. (2015). Biology of Zika Virus Infection in Human Skin Cells. Journal of Virology, 89(17), 8880-8896. https://doi.org/10.1128/JVI.00354-15

Higuchi, T., Seki, N., Kamizono, S., Yamada, A., Kimura, A., Kato, H., \& Itoh, K. (1998). Polymorphism of the 5'-flanking region of the human tumor necrosis factor (TNF)- $\alpha$ gene in Japanese. Tissue Antigens, 51(6), 605-612. https://doi.org/10.1111/J.1399-0039.1998.TB03002.X

Kam, Y. W., Leite, J. A., Lum, F. M., Tan, J. J. L., Lee, B., Judice, C. C., De Toledo Teixeira, D. A., Andreata-Santos, R., Vinolo, M. A., Angerami, R., Resende, M. R., Freitas, A. R. R., Amaral, E., Passini, R., Costa, M. L., Guida, J. P., Arns, C. W., Ferreira, L. C. S., Rénia, L., ... Costa, F. T. M. (2017). Specific biomarkers associated with neurological complications and congenital central nervous system abnormalities from Zika virus-infected patients in Brazil. Journal of Infectious Diseases, 216(2). https://doi.org/10.1093/infdis/jix261 
Kasztelewicz, B., Czech-Kowalska, J., Lipka, B., Milewska-Bobula, B., Borszewska-Kornacka, M. K., Romańska, J., \& Dzierżanowska-Fangrat, K. (2017). Cytokine gene polymorphism associations with congenital cytomegalovirus infection and sensorineural hearing loss. European Journal of Clinical Microbiology \& Infectious Diseases 2017 36:10, 36(10), 1811-1818. https://doi.org/10.1007/S10096-017-2996-6

Kerui, V., Lin, L., Ai, Q., Wan, J., Dai, J., Liu, G., Tang, L., Yang, Y., Ge, P., Jiang, R., \& Zhang, L. (2018). Lipopolysaccharide-Induced Dephosphorylation of AMPK-Activated Protein Kinase Potentiates Inflammatory Injury via Repression of ULK1-Dependent Autophagy. Frontiers in Immunology, 9(JUN). https://doi.org/10.3389/FIMMU.2018.01464

Kindberg, E., Vene, S., Mickiene, A., Lundkvist, Å., Lindquist, L., \& Svensson, L. (2011). A Functional Toll-Like Receptor 3 Gene (TLR3) May Be a Risk Factor for Tick-borne Encephalitis Virus (TBEV) Infection. The Journal of Infectious Diseases, 203(4), 523-528. https://doi.org/10.1093/INFDIS/JIQ082

Kumar, A., Giri, S., \& Kumar, A. (2016a). 5-Aminoimidazole-4-carboxamide ribonucleoside-mediated adenosine monophosphate-activated protein kinase activation induces protective innate responses in bacterial endophthalmitis. Cellular Microbiology, 18(12), 1815-1830. https://doi.org/10.1111/CMI.12625

Kumar, A., Giri, S., \& Kumar, A. (2016b). AICAR-mediated AMPK activation induces protective innate responses in bacterial endophthalmitis. Cellular Microbiology, 18(12), 1815. https://doi.org/10.1111/CMI.12625

Liberati, A., Altman, D. G., Tetzlaff, J., Mulrow, C., Gøtzsche, P. C., Ioannidis, J. P. A., Clarke, M., Devereaux, P. J., Kleijnen, J., \& Moher, D. (2009). The PRISMA statement for reporting systematic reviews and meta-analyses of studies that evaluate health care interventions: explanation and elaboration. Journal of Clinical Epidemiology, 62(10), e1-e34. https://doi.org/10.1016/J.JCLINEPI.2009.06.006

Lum, F. M., Narang, V., Hue, S., Chen, J., McGovern, N., Rajarethinam, R., Tan, J. J. L., Amrun, S. N., Chan, Y. H., Lee, C. Y. P., Chua, T. K., Yee, W. X., Yeo, N. K. W., Tan, T. C., Liu, X., Haldenby, S., Leo, Y. sin, Ginhoux, F., Chan, J. K. Y., ... Ng, L. F. P. (2019). Immunological observations and transcriptomic analysis of trimester-specific full-term placentas from three Zika virus-infected women. Clinical and Translational Immunology, 8(11), 1-15. https://doi.org/10.1002/cti2.1082

Maciel, I. J., Júnior, J. B. S., \& Martelli, C. M. T. (2008). Epidemiologia e desafios no controle do dengue. Revista de Patologia Tropical / Journal of Tropical Pathology, 37(2), 111-130. https://doi.org/10.5216/RPT.V37I2.4998

Moher, D., Liberati, A., Tetzlaff, J., \& Altman, D. (2009). Preferred reporting items for systematic reviews and meta-analyses: the PRISMA statement. PLoS Medicine, 6(7). https://doi.org/10.1371/JOURNAL.PMED.1000097

Moreira, D., Silvestre, R., da Silva, A., Estaquier, J., Foretz, M., \& Viollet, B. (2016). AMP-activated Protein Kinase As a Target For Pathogens: Friends Or Foes? Current Drug Targets, 17(8), 942-953. https://doi.org/10.2174/1389450116666150416120559

Musso, D., Cao-Lormeau, V. M., \& Gubler, D. J. (2015). Zika virus: Following the path of dengue and chikungunya? In The Lancet (Vol. 386, Issue 9990, pp. 243-244). Lancet Publishing Group. https://doi.org/10.1016/S0140-6736(15)61273-9

Naveca, F. G., Pontes, G. S., Chang, A. Y. H., da Silva, G. A. V., do Nascimento, V. A., Monteiro, D. C. da S., da Silva, M. S., Abdalla, L. F., Santos, J. H. A., de Almeida, T. A. P., Mejía, M. del C. C., de Mesquita, T. G. R., Encarnação, H. V. de S., Gomes, M. de S., Amaral, L. R., Campi-Azevedo, A. C., CoelhoDos-Reis, J. G., Antonelli, L. R. do V., Teixeira-Carvalho, A., ... Ramasawmy, R. (2018). Analysis of the immunological biomarker profile during acute zika virus infection reveals the overexpression of CXCL10, a chemokine linked to neuronal damage. Memorias Do Instituto Oswaldo Cruz, 113(6). https://doi.org/10.1590/0074-02760170542

Nem de Oliveira Souza, I., Frost, P. S., França, J. V, Nascimento-Viana, J. B., Neris, R. L. S., Freitas, L., Pinheiro, D. J. L. L., Nogueira, C. O., Neves, G., Chimelli, L., De Felice, F. G., Cavalheiro, É. A., Ferreira, S. T., Assunção-Miranda, I., Figueiredo, C. P., Da Poian, A. T., \& Clarke, J. R. (2018). Acute and chronic neurological consequences of early-life Zika virus infection in mice. Science Translational Medicine, 10(444). https://doi.org/10.1126/scitranslmed.aar2749

Ojha, C. R., Rodriguez, M., Lapierre, J., Karuppan, M. K. M., Branscome, H., Kashanchi, F., \& El-Hage, N. (2018). Complementary mechanisms potentially involved in the pathology of Zika virus. In Frontiers in Immunology (Vol. 9, Issue OCT, p. 2340). Frontiers Media S.A. https://doi.org/10.3389/fimmu.2018.02340

Petrônio, C. N. V., Melo, A. M. D. de, Mesquita Neto, E., Sampaio, J. A. A., Telles, M. V. L., \& Souza, C. M. S. C. de. (2018). O Início da Epidemia do Zika Vírus e os seus Reflexos na Saúde Pública Nacional e Internacional. Id on Line Revista De Psicologia, 12(40), 1232-1235. https://doi.org/10.14295/idonline.v12i40.1188

Rabelo, K., Souza, L. J., Salomão, N., Machado, L., Pereira, P., Portari, E., Oliveira, R., Santos, F., Neves, L., Morgade, L., Provance Jr., D., Mendonça, L., \& Paes, M. (2020). Zika Induces Human Placental Damage and Inflammation. Frontiers in Immunology, 11. https://doi.org/10.3389/FIMMU.2020.02146

Rabelo, K., Souza, L., Salomão, N., Oliveira, E., Sentinelli, L., Lacerda, M., Saraquino, P., Rosman, F., Oliveira, R., Carvalho, J., \& Paes, M. (2018). Placental Inflammation and Fetal Injury in a Rare Zika Case Associated With Guillain-Barré Syndrome and Abortion. Frontiers in Microbiology, 9(MAY). https://doi.org/10.3389/FMICB.2018.01018

Santos, C. N. O., Ribeiro, D. R., Cardoso Alves, J., Cazzaniga, R. A., Magalhães, L. S., De Souza, M. S. F., Fonseca, A. B. L., Bispo, A. J. B., Porto, R. L. S., Santos, C. A. Dos, Da Silva, Â. M., Teixeira, M. M., De Almeida, R. P., \& De Jesus, A. R. (2019). Association between Zika Virus Microcephaly in Newborns with the rs3775291 Variant in Toll-Like Receptor 3 and rs 1799964 Variant at Tumor Necrosis Factor- $\alpha$ Gene. Journal of Infectious Diseases, 220(11), 17971801. https://doi.org/10.1093/infdis/jiz392

Schriefer, A., \& Carvalho, E. M. (2008). Biomarcadores em Medicina Biomarcadores em Medicina Biomarcadores em Medicina Biomarcadores em Medicina Biomarcadores em Medicina Biomarkers in Medicine.

Silva, L. B., dos Santos Neto, A. P., Maia, S. M. A. S., dos Santos Guimarães, C., Quidute, I. L., Carvalho, A. de A. T., Júnior, S. A., \& Leão, J. C. (2019). The Role of TNF- $\alpha$ as a Proinflammatory Cytokine in Pathological Processes. The Open Dentistry Journal, 13(1), 332-338. https://doi.org/10.2174/1874210601913010332 
Research, Society and Development, v. 10, n. 10, e428101019080, 2021

(CC BY 4.0) | ISSN 2525-3409 | DOI: http://dx.doi.org/10.33448/rsd-v10i10.19080

Silva, M., Costa, H., Valadares, B., Grecchi, L., Nagao, L., \& Santos, G. (2019). Overview of Brazilian Requirements for Therapeutic Equivalence of Orally Inhaled and Nasal Drug Products. AAPS PharmSciTech, 20(6), 1-7.

Singh, S., Singh, P., Suhail, H., Arumugaswami, V., Pellett, P., Giri, S., \& Kumar, A. (2020). AMP-Activated Protein Kinase Restricts Zika Virus Replication in Endothelial Cells by Potentiating Innate Antiviral Responses and Inhibiting Glycolysis. Journal of Immunology (Baltimore, Md. : 1950), 204(7), 1810-1824. https://doi.org/10.4049/JIMMUNOL.1901310

Sironi, M., Biasin, M., Cagliani, R., Forni, D., Luca, M. De, Saulle, I., Caputo, S. Lo, Mazzotta, F., Macías, J., Pineda, J. A., Caruz, A., \& Clerici, M. (2012). A Common Polymorphism in TLR3 Confers Natural Resistance to HIV-1 Infection. The Journal of Immunology, 188(2), 818-823. https://doi.org/10.4049/JIMMUNOL.1102179

Studzińska, M., Jabłońska, A., Wiśniewska-Ligier, M., Nowakowska, D., Gaj, Z., Leśnikowski, Z. J., Woźniakowska-Gęsicka, T., Wilczyński, J., \& Paradowska, E. (2017). Association of TLR3 L412F Polymorphism with Cytomegalovirus Infection in Children. PLOS ONE, 12(1), e0169420. https://doi.org/10.1371/JOURNAL.PONE.0169420

Tang, H., Hammack, C., Ogden, S. C., Wen, Z., Qian, X., Li, Y., Yao, B., Shin, J., Zhang, F., Lee, E. M., Christian, K. M., Didier, R. A., Jin, P., Song, H., \& Ming, G. L. (2016). Zika Virus Infects Human Cortical Neural Progenitors and Attenuates Their Growth. Cell Stem Cell, 18(5), 587-590. https://doi.org/10.1016/J.STEM.2016.02.016

Vinhaes, C. L., Arriaga, M. B., de Almeida, B. L., Oliveira, J. V., Santos, C. S., Calcagno, J. I., Carvalho, T. X., Giovanetti, M., Alcantara, L. C. J., de Siqueira, I. C., \& Andrade, B. B. (2020). Newborns with zika virus-associated microcephaly exhibit marked systemic inflammatory imbalance. Journal of Infectious Diseases, 222(4). https://doi.org/10.1093/infdis/jiaa197 